\title{
Superorganisms of the Protist Kingdom: A New Level of Biological Organization
}

\author{
Łukasz Lamża ${ }^{1}$ \\ Published online: 24 July 2020 \\ (c) The Author(s) 2020
}

\begin{abstract}
The concept of superorganism has a mixed reputation in biology-for some it is a convenient way of discussing supra-organismal levels of organization, and for others, little more than a poetic metaphor. Here, I show that a considerable step forward in the understanding of superorganisms results from a thorough review of the supra-organismal levels of organization now known to exist among the "unicellular" protists. Limiting the discussion to protists has enormous advantages: their bodies are very well studied and relatively simple (as compared to humans or termites, two standard examples in most discussions about superorganisms), and they exhibit an enormous diversity of anatomies and lifestyles. This allows for unprecedented resolution in describing forms of supra-organismal organization. Here, four criteria are used to differentiate loose, incidental associations of hosts with their microbiota from "actual" superorganisms: (1) obligatory character, (2) specific spatial localization of microbiota, (3) presence of attachment structures and (4) signs of co-evolution in phylogenetic analyses. Three groups - that have never before been described in the philosophical literature-merit special attention: Symbiontida (also called Postgaardea), Oxymonadida and Parabasalia. Specifically, it is argued that in certain cases-for Bihospites bacati and Calkinsia aureus (symbiontids), Streblomastix strix (an oxymonad), Joenia annectens and Mixotricha paradoxa (parabasalids) and Kentrophoros (a ciliate) — it is fully appropriate to describe the whole protist-microbiota assocation as a single organism ("superorganism") and its elements as "tissues" or, arguably, even "organs". To account for this level of biological complexity, I propose the term "structured superorganism".
\end{abstract}

Keywords Superorganism $\cdot$ Holobiont $\cdot$ Protista $\cdot$ Symbiontida $\cdot$ Oxymonadida $\cdot$ Parabasalia

Łukasz Lamża

lukasz.lamza@uj.edu.pl

1 Copernicus Center for Interdisciplinary Studies, Jagiellonian University in Krakow, Kraków, Poland 


\section{Introduction}

By the end of the twentieth century it has become clear that all organisms live in close association-metabolic, functional, physical—with other organisms. In fact, based on microscopic imaging of actual living environments, a solitary organism not physically covered by other organisms (esp. microorganisms) is the rare exception, not the norm (Dyer and Khalsa 1993, p. 179). A second important conceptual breakthrough was the confirmation of the endosymbiotic theory, i.e. the proposition that certain subcellular organelles of eukaryotes, esp. the mitochondrion and various types of chloroplasts, are derived from free-living prokaryotes, so that a single eukaryotic cell usually contains genetic material from multiple different organisms.

This led to the growing need for an expanded terminology for this supra-organismal level of biological organization. Hence terms such as "superorganism", "holobiont" and "hologenome" (Wilson and Sober 1989; Margulis 1991; Gordon et al. 2013). While some authors are enthusiastic to use and expand this new language-leading to what has been characterized as a "superorganism revival" (Haber 2013)-others see it as little more that "poetic metaphors in scientific guise" (Wilson and Sober 1989). It is still very much an open question whether physical associations of organisms should be described as a single organism. A related problem arises concerning the concepts of self and individuality - is the organism-microbiota association a single "biological individual" [Hull 1988; Pradeu 2012]?

The purpose of this paper is to review the current state of knowledge concerning supra-organismal associations amongst microscopic eukaryotes, with special focus on cases where the "host" is a unicellular protist, in order to shed some light on the applicability and practicality of the term "superorganism". Protists are relatively little known by philosophers of biology and at the same time offer some of the most spectacular examples of supra-organismal organization in life. Based on several well-studied examples it will be easy to demonstrate their full range of functional and morphological integration and discuss the applicability of the term "superorganism" and "individual" to protist-microbiota associations.

\section{Terminology}

Lynn Margulis, who coined the term "holobiont", defined it as a "symbiont compound of recognizable bionts", where the symbiotic association is to be maintained "throughout a significant portion of the life history" (Margulis 1991). Simply put, if a symbiosis entails continuous physical contact between organisms, the resulting association is a holobiont. Just how close the physical association has to be is not specified-and will be one of the subjects of the present study. Two decades later Margulis revisited the issue in an article co-authored with R. Guerrero and M. Berlanga (Guerrero et al. 2013). Holobiont was defined as a "permanent coexistence of various bionts", and in the same paper the additional term "holobiome" was defined as "the sum total of the component genomes in a eukaryotic organism; it comprises the genome of an individual member of a given taxon (the host genome) and the microbiome (the genomes of the symbiotic microbiota)". This is equivalent to the term "hologenome", as originally defined by Rosenberg and Zilber-Rosenberg (2011): "hologenome is the sum of the genetic 
information of the host and its microbiota", later expanded in Rosenberg and ZilberRosenberg (2014).

The term "superorganism" has two distinct meanings. First and foremost, it is used to describe groups of same-species individuals when they are to be treated "as a single organism" (what that specifically means is notoriously difficult to define but is luckily beyond the scope of the present study). Here, such a concept will be referred to as a single-species superoorganism. Gordon et al. (2013) employ this very definition: "The «super» in superorganism denotes a higher level of organization, an association composed of multiple organisms of the same species". The prototypical example is a colony of eusocial insects. In fact, it is sometimes claimed that the term "superorganism" itself was coined in 1928 by the myrmecologist William Morton specifically to refer to colonies of ants (Gordon et al. 2013). Other commonly discussed examples of superorganisms include slime molds (Wilson and Sober 1989; Linksvayer et al. 2013) and human societies (Kesebir 2012). There is an interesting paper by Trenchard (2015), where the peloton formed by cyclists is modeled and described as a superorganism.

Some authors extend the notion of superorganism to include any association of individuals that behaves as a single organism, including multi-species ones. Wilson and Sober (1989) propose the following definition: "we define superorganism as a collection of single creatures that together possess the functional organization implicit in the formal definition of organism", where the term "organism" is to be understood as "a form of life composed of mutually dependent parts that maintain various vital processes". The canonical example of a superorganism of that kind, i.e., a multi-species superorganism, is the human-human microbiota complex, but there are other well known cases, such as the coral-zooxanthella-microbiome complex (Gordon et al. 2013). Although some authors continue to oppose this usage, underscoring that "the term [superorganism] is exclusively used in the context of an assembly of multiple individuals from the same species, such as in colony-forming ants, wasps, bees and termites" and, therefore "the holobiont is not a superorganism" (Bordestein and Theis 2015), that word is in fact commonly used to describe multi-species associations. For instance, referring to the human-microbiome association as a "superorganism" has become commonplace in nutrition science and gastroenterology (e.g. Goodacre 2007; Mai and Draganov 2009; Dietert and Dietert 2012). One may also find the term "superorganism" used in the literature in the broad, indiscriminate sense (Wilson and Sober 1989), to refer to both same-species and multi-species associations (Fig. 1).

In the vast literature in philosophy of biology that deals with the issue of self-nonself and individuality (see e.g. Bouchard and Huneman (2013) for a recent review), there are competing definitions of what constitutes an individual. Pradeu (2012, p. 230) synthetically groups these definitions into three categories, based on the method of individuating: (a) phenomenal individuation; (b) physiological individuation; (c) evolutionary individuation. The first method is rightfully characterized as commonsense and only the latter two will be important for the present study. A physiological individual is a "functionally integrated unit" that is "made up of causally interconnected elements"; to divide the biological world into physiological individuals, the input from anatomists and physiologists is needed. Interestingly, immunology provides a very specific criterion for physiological individuality: an organism's immune system distinguishes self from non-self by either protecting or rejecting a given biological entity. Hence "immunological individuals" (Pradeu 2012, 2016). An evolutionary individual is "any entity upon which natural selection acts". A related term is interactor: "an entity that interacts as a cohesive whole with its environment in such a way that this interaction causes replication to be differential" (Hull 1988). 


\section{SUPERORGANISM sensu lato}

"a collection of single creatures that together possess the functional organization implicit in the formal definition of organism" (Wilson and Sober 1989)
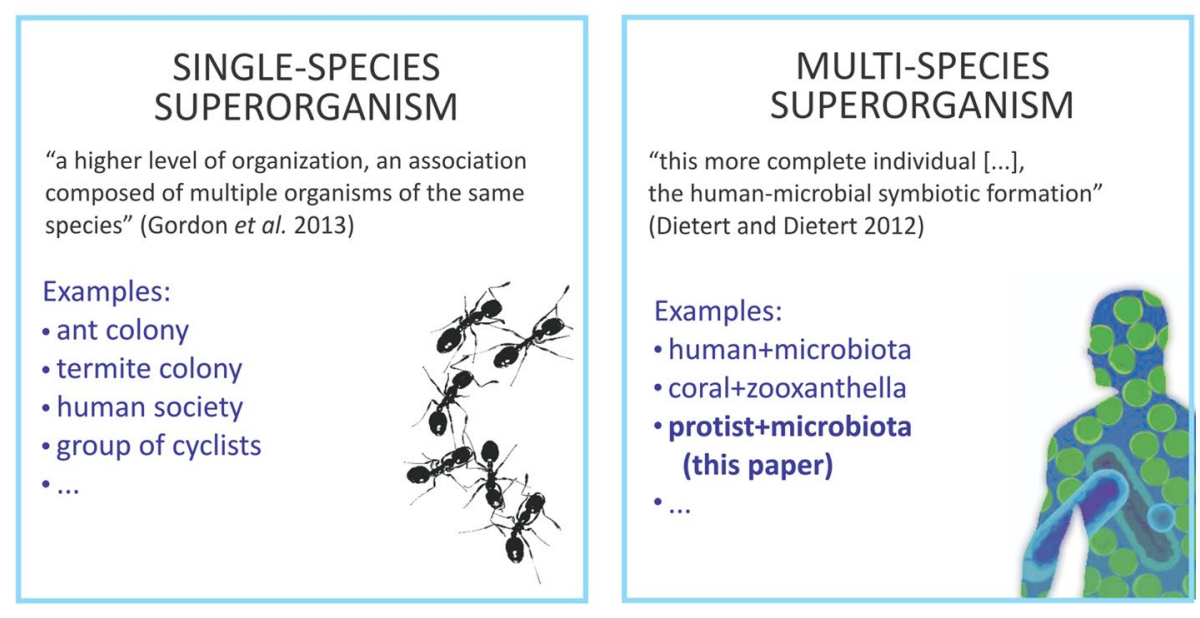

Fig. 1 A summary of the various meanings of the term "superorganism" discussed in the article

Finally, there are three simple concepts from elementary biology that are non-controversial and very useful for the present study. Epibiotic organisms are those who live on the surface of another organism, called the host (whether it is beneficial to the host, or not). Endobiotic organisms live inside the host, which in the context of protist-based associations, will mean: inside the cell, i.e. in the cytoplasm (or, sometimes, inside the cell nucleus); again, this may be beneficial, neutral or detrimental to the host. Endosymbiont is an endobiotic symbiont.

Here, the term "physical association" or simply "association" will be used to denote any group of organisms that are in direct physical contact, with no further stipulations whatsoever.

\section{Superorganisms of the Protist Kingdom-An Introduction for the Non-protistologist}

"Protista" is a name given traditionally to a huge, diverse assemblage of species that have morphologically, ecologically and ultrastructurally very little in common. An evolutionary ("phylogenetic") definition of Protista is as follows: consider all eukaryotes, i.e. all living organisms that have cell nuclei (alongside other subcellular structures, almost always present in Eukaryota, such as mitochondria or the Golgi apparatus). Eukaryotes evolved from prokaryotes which include all "bacteria" (now known to actually comprise two distinct 
groups: the "true" bacteria, i.e. Eubacteria, and archaeans, Archaea). The clade Eukaryota includes the three well-known multicellular kingdoms: Animalia, Plantae and Fungi and everything that is left: a heterogeneous assemblage called Protista. Although it was originally thought that protists are "simplified" animals, plants and fungi (hence names such as "Protozoa"), it is now known that they are creatures of extraordinary complexity and diversity.

There are hundreds of known cases of protist-prokaryote associations, but the following four groups will be described especially closely: Oxymonada, Parabasalia, Symbiontida and certain ciliates (Ciliophora).

There are ca. 150 species of oxymonads (see: Hampl (2017) for a review), most of which are inhabitants of termite hindguts, occasionally occurring also in digestive tracts of other animals. Their cells are almost fully covered by hundreds of rod-shaped epibiotic bacteria which form a tight, continuous envelope-see Fig. 2a. The body of the host is reduced and contains numerous thin "vanes", radiating from a narrow center core, which gives it a large surface area. Bacteria are attached to the oxymonad body in specific locations, demarcated by special host-produced "knobs" (Leander and Keeling 2004). An oxymonad "healed" by antibiotics of its bacterial envelope, quickly changes shape and deteriorates (Noda et al. 2006). In some species epibiotic bacteria function as a chemosensor, informing the host about chemical gradients in the environment (Dyer and Khalsa 1993). In addition, there is a wide variety of endobiotic bacteria inhabiting the oxymonad cytoplasm.

Parabasalids are multiflagellate inhabitants of the guts of termites and the closely related wood-feeding roach Cryptocercus [see: Čepička et al. (2017) for a review]. There are ca. 450 species currently recognized. They are hosts to a wide variery of ecto- and endobiotic bateria (see Fig. 2b), playing various functions, including locomotion, chemical protection and metabolic cooperation.

Symbiontida is a recently established grouping of 3 species, closely related to Euglenozoa, that live in low-oxygen or anoxic sediments [see: Leander and Yubuki (2018) for a review]. They are fully covered by epibiotic bacteria, and their plasma membrane is underlain by specialized organelles that facilitate exchange of metabolites between the bacteria and the host. In the symbiontid Bihospites bacati (Fig. 2c) there are two distinct species of epibionts with different functions and arranged on the surface in distinct longitudinal bands (Breglia et al. 2010).

There are ca. 3500 described species of ciliates [see: Lynn (2008) for a review] and many of them associate with epi- and endobiotic prokaryotes. Here, two main examples of such associations will be discussed. First, highly specialized surface-attached bacteria, belonging to the phylum Verrucomicrobia, that in the context of ciliate anatomy are called epixenosomes, and play a defensive function for the host (Petroni et al. 2000). Second, extremely complex organelle-like objects, found in certain anoxic ciliates, that are composed of multiple species of prokaryotes, and have many features of multicellular organs (Edgcomb et al. 2011a, b) these will be discussed in Sect. 6 .

\section{Why Protists?}

Protists are the main focus of the present analysis for a number of reasons. First, many of them are relatively little known to philosophers of biology, and are rarely, or never, mentioned in discussions about superorganisms, holobionts and biological individuality (with the notable exception of termite gut microbiota, where, however, the protists are usually 
discussed as the microbiota and the termite as a host). In practice, there is a number of "standard" examples discussed in that context—see Sect. 2 above—-that are analyzed from multiple theoretical perspectives, but there seems to be little awareness of the actual range of structural and functional diversity of eukaryotic supra-organismal associations. To the best of my knowledge, some of the most interesting, complex and relevant examples, such as the patterned multi-species epibiotic "skins" of the symbiontid protists, or the "organs" found in certain dinozoans and anoxic ciliates (see Sect. 6 below) - have not yet been discussed in the context of the problem of the superorganism. Yet it is precisely such cases that should inform the discussion about the applicability of terms such as "superorganism".

The second reason is that single-celled protists associated with other single-celled organisms (mostly bacteria, but also archaea and other eukaryotes) provide a convenient object of study. The human superorganism, for instance, is extremely complex, with trillions of human and non-human cells interacting in multiple ways. Over 600 species of prokaryotes have been identified in the human oral cavity alone (Chen et al. 2010). In contrast, a single protist cell may be fully imaged by scanning electron microscope (SEM), and then by transmission electron microscope (TEM), revealing at once its full population of epibiotic and endobiotic partners. Also, for the purpose of discovering functional relationships in a protist-microbione holobiont, it is relatively easy to, say, remove all surface bacteria from a protist, and observe the consequences (Noda et al. 2006). One cannot do this with human subjects, and, as a consequence, the exact role played by the given group of bacteria living, for instance, on a human tongue, is not easy to determine. Are they simply opportunistic commensals, or do they play a functional role for the human host? As a result, the actual structure and function of the human superoorganism are in fact unknown. At the same time, it is becoming increasingly obvious that study of microorganisms as such is of critical importance when one wishes to arrive at a satisfactory understanding of what an "organism" really is (e.g. Stencel and Proszewska 2018). Protists are a perfect source of inspiration and raw biological facts for that very discussion.

\section{From Incidental Associations to Integrated Superorganisms}

The major problem when trying to decide on the reality of "superorganisms" is the existence of incidental, "casual" physical associations between organisms. As mentioned in the opening paragraph, it is to be expected that on any moist surface there will be microbes, and in crowded spaces, such as termite hindguts, or in marine sands, we may expect that a randomly selected protist will have a number of prokaryotes on its surface (Dyer and Khalsa 1993, p. 179). How to decide whether this is simply an incidental association that has no biological function, or the resulting association is indeed a functional whole, i.e. a superorganism?

After reviewing the current state of knowledge about supra-organismal associations in the protist kingdom, I propose the four hallmarks of a stable, actively maintained, functional association that merits the use of the term "superorganism":

- negative consequences of separation;

- selectivity of ecto- and endobiont localization;

- presence of specialized attachment points in the host;

- signs of co-evolution in phylogenetic analyses. 
These will be now discussed in detail to clearly separate candidate "superorganisms" from mere accidental associations of cells, and to present the range of speciesspecies integration found in the protist kingdom.

\subsection{Negative Consequences of Separation}

One cannot speak of an organism (and, therefore, superorganism) if one of its main constituent parts can be removed without any negative consequences for the whole. In protist-prokaryote associations, the whole spectrum of levels of dependence can be observed.

At the lowest level, the association between the organisms is purely incidental, and there are no detectable negative consequences of their separation. Rosowski and Langenberg (1994) observed a population of rod-like bacteria on a surface of an euglenozoan Trachelomonas grandis. Hundreds of individual bacterial cells were present and the authors attempted to find out whether this is a symbiotic relationship. Later analyses showed that Trachelomonas can be grown without the bacteria and that in fact in natural populations the epibionts may become spontaneously lost (Rosowski and Couté 1996).

Another example: Paramecium often hosts numerous endobiotic bacteria, interspersed in its cytoplasm. These are separated between daughter cells after cell division. For some strains (Preer et al. 1974) there is no control over the separation of endobionts during cell divison and some daughter cells may contain no bacterial cells of a given strain whatsover: the endobiont is effectively "lost". Sometimes, it is later re-acquired, but in other cases a line of ciliates will be completely devoid of them without any noticeable negative consequences.

Sometimes the loss of the symbiont leads to diminished survivability. The ciliate Euplotidium (Petroni et al. 2000) contains on its surface bacterial cells that defend their host against the ciliate predator Litonotus lamella. The bacteria, called "epixenosomes" in the context of ciliate anatomy, eject-in response to a proper signal which may be chemical or mechanical — a thin rigid rod, up to $30 \mu \mathrm{m}$ in length that pierces the approaching predator. In the absence of epixenosomes, the ciliate easily falls prey to Litonotus, but is otherwise viable.

Finally, there are cases where the symbiosis is strictly obligatory and its disruption leads to certain death. Attempts to "cure" the oxymonad Streblomastix strix of its bacterial cover with the antibiotic carbenecillin leads to dramatic consequences (Leander and Keeling 2004). First, the normally slim cell of the protist (see Fig. 2a) puffs up and becomes teardrop-shaped. After 3-4 days of "treatment" all cells of S. strix were dead.

\subsection{Specificity of Localization}

There are instances of host-epibiont relationship where there seems to be no spatial order in their association. In the above-mentioned example of $T$. grandis, the authors describe the total lack of order in the localization of the bacteria which had no specificity with regards to the region of the attachment (Rosowski and Langenberg 1994). Host's anatomy doesn't seem to influence epibiont location in any way. 
Also, there are numerous examples of endosymbiosis where there is no visible order in the location of endobionts. This is, in fact, a fairly common situation in the protist kingdom; in a recent review endosymbiosis was in fact called "a general evolutionary strategy of protists", and in typical cases there is no particular spatial order in the arrangement of the endobionts (Nowack and Melkonian 2010). For instance, a cercozoan amoeba Paulinella chromatophora hosts photosynthetic cyanobacterial endobionts that are randomly interspersed in its cytoplasm.

In contrast, epibionts associated with all oxymonads, parabasalids, and symbiontids are located in highly specialized zones. As mentioned above, the symbiontid Bihospites bacati (see Figs. 2c and 3) hosts populations of two bacterial species (Breglia et al. 2010): one is rod-shaped and one spherical. The two species are arranged in alternating longitudinal stripes which gives the protist a zebra-like look. The rod-shaped bacteria are all arranged parallel to each other, and the spherical bacteria form a row that is either one-cell or twocells wide. The protist is fully covered, save for a small region surrounding of the cytostome, called vestibulum, which is completely epibiont-free. The oxymonad Streblomastix strix contains a naked "bulb" in its anterior part that is devoid of ectobiotic bacteria; the rest of its body is completely covered by them (Leander and Keeling 2004). This is clearly a sign of tight spatial control over the localization of epibionts.

The unusual ciliate Kentrophoros (Foissner 1995) hosts epibiotic bacteria that live only on a specific side of its body, inside a sharply delimited "plot". The bacteria are attached to the ciliate by a layer of host-produced mucus, and are successively phagocytosed by it and digested. The ciliate has a strongly simplified oral apparatus and is unable to obtain food in the normal way, so it fully dependent on the bacteria as the source of its food. Simply put, it is "a mouthless ciliate with a symbiotic kitchen garden", as it was vividly described in the title of one paper (Fenchel and Finlay 1989).

\subsection{Presence of Specialized Attachment Structures}

There is probably no better sign of host activity in the maintenance of an epibiont population then the presence of specialized surface structures. The oxymonad Streblomastix strix produces special surface protrusions (called "knobs") that abut its rod-shaped epibiotic bacteria (Leander and Keeling 2004). Individual bacteria are in effect held in place by their tips, in a matter visually similar to how AA batteries are held in a socket. The parabasalid Mixotricha paradoxa creates semi-circular projections of the plasma membrane, called "brackets" to which its ectosymbiotic spirochaetes are attached (Cleveland and Grimstone 1964), exactly one bracket per one bacterium. The spirochaetes themselves have enlarged, bulbous tips at the point of contact with the host, which is not the usual anatomical state for these prokaryotes. Therefore, both the host and the ectobiont possess special attachment structures.

The symbiontid Calkinsia aureus (Yubuki et al. 2009) is covered by a thick (100 nm) extracellular matrix (which, incidentally, gives it a beautiful orange color), over which are arranged rod-shaped bacteria, totally covering its body, save for the region immediately surrounding the cytostome. The matrix is underlain by mitochondrion-like organelles, and there are tunnel-like perforations in the matrix that connect the epibiotic bacteria with the organelles. These conduits are most likely involved in metabolic exchange between the prokaryotes outside and the mitochondrion-like organelles inside.

There are other examples and, generally speaking, an ultrastructural study of an obligatory protist-microbe association usually leads to the discovery of specialized attachment 


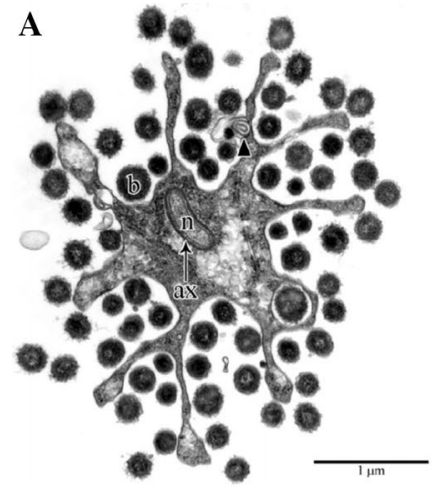

B

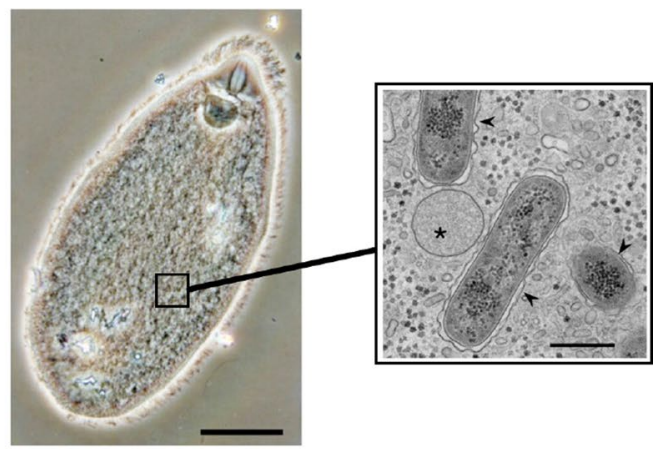

C
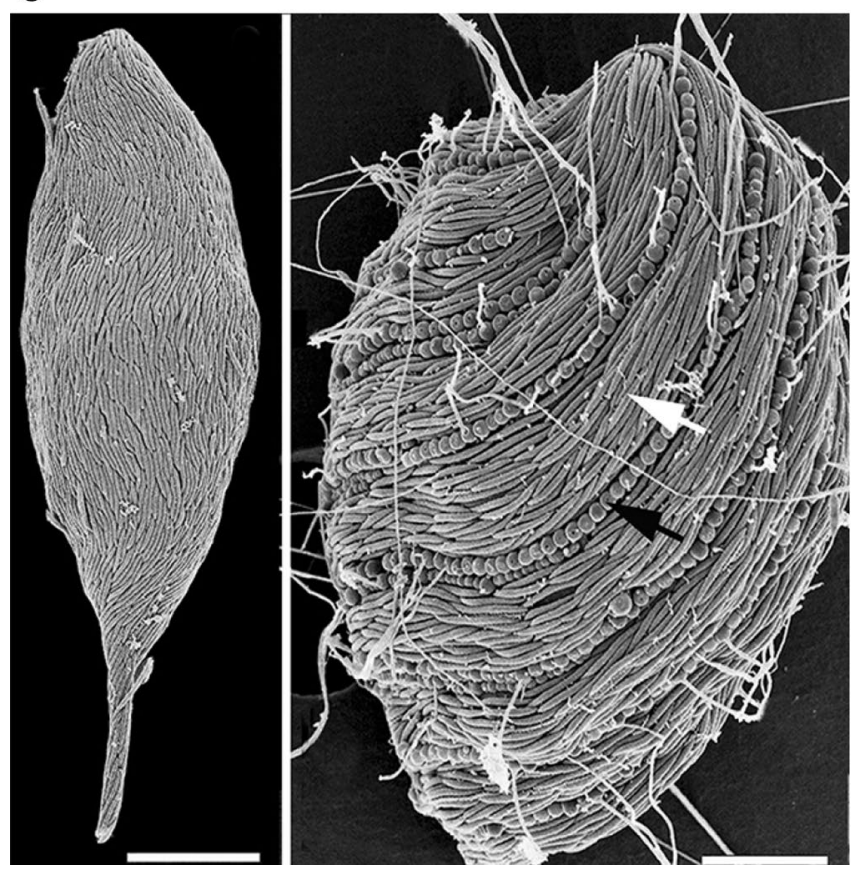

Fig. 2 a A cross-section of a single cell of an oxymonad Streblomastix strix [from: Treitli et al. 2019]. The stellate structure in the center is the cell of the oxymonad itself. The surrounding black dots are individual bacterial cells covering the protist. b A single cell of a parabasalid Eucomonympha [from: Ohkuma et al. 2015]. This protist contains both surface-attached bacteria (not visible) and endobiotic bacteria (shown in magnification, arrowheads). c Members of Symbiontida: Calkinsia aureus (left) and Bihospites bacati (right) [from: Yubuki and Leander (2018)], fully covered by surface-attached bacteria. In C. aureus it is a single morphotype. $B$. bacati has ectobionts of two separate types: black arrows show spherical-shaped bacteria and white arrows: rod-shaped. Long white filaments are most likely defense structures ejected by the protist before preparation

structures. The parabasalid Joenia annectens hosts at least 4, and sometimes up to 6 different species of prokaryotes, including both eubacteria and archaea (Strassert et al. 2010). In places at the cell surface where the epibionts are attached the cell membrane is underlain 

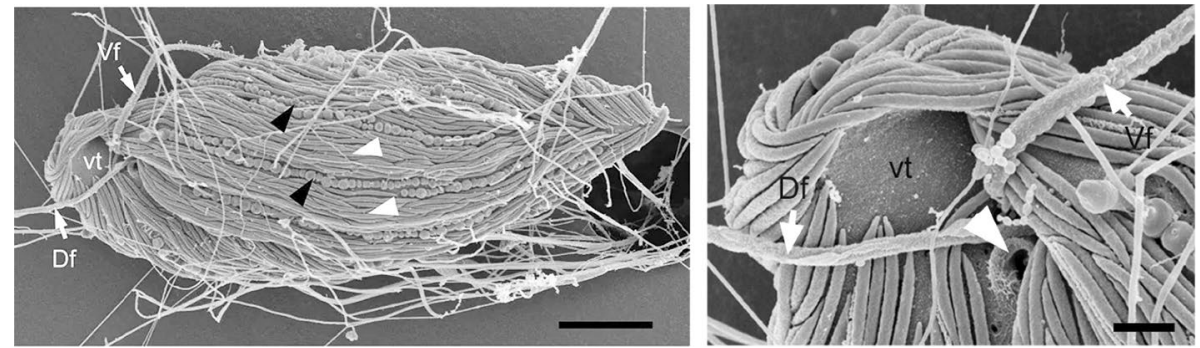

Fig. 3 A cell of Bihospites bacati and its ectobiotic bacteria [from: Breglia et al. 2010]. The image on the left shows the characteristic "zebra-stripe" arrangement of the two morphotypes of the bacteria. The image on the right shows the vestibulum (vt) - the naked, bacteria-free area immediately surrounding the cytostome (i.e. "mouth"). Both images demonstrate that the location of the bacteria are tightly controlled by the host and/or the bacteria (or, in the language of the present paper, by the superorganism itself)

by an electron-dense layer. Epixenosomes of the ciliate Euplotidium are located in shallow cell invaginations, also underlain by an electron-dense layer (Petroni et al. 2000, their Fig. 3c).

\subsection{Signs of Co-evolution}

Any stable long-term relationship between species might be expected to lead to co-evolution. This is especially important in the context of those theoretical analyses of the concept of superorganism that underscore "group adaptation" (e.g. Gardner and Grafen 2009)—if the group really is a unit of evolutionary processes, it should become apparent in phylogenetic analyses. For instance, parallel speciations might be expected: in a host-partner pair, if the host speciates, and there is host-partner specificity, we should expect the partner to also speciate. This is a known effect in insect-plant symbioses [see Winkler and Mitter (2008) for a comprehensive review]. It seems that the same effect occurs in protist-prokaryote associations.

First, there are clear signs of species-selectivity. Closely related species of oxymonads, living in the same environment, with access to the same species of prokaryotes, will have wildly different relationships with them. For instance, members of the genus Saccinobaculus will generally not have epibiotic bacteria on their surfaces, even though they inhabit the hindgut of the wood-feeding cockroach Cryptocercus that is also inhabited by oxymonads that do have epibiotic bacteria (Hampl 2017). In a different study, Noda et al. (2006) discovered that two closely related and highly anatomically similar species of oxymonads, Hoplonympha sp. and Streblomastix sp., diplayed clear preference for different strains of bacteria.

Second, parallel speciation has actually been demonstrated. In a careful phylogenetic study of the parabasalian genus Devescovina, and its bacterial ectosymbionts of the order Bacteroidales (Desai et al. 2010), it was discovered that the branching order of 9 parabasalid species is exactly mirrored by the branching order of 9 bacterial strains (and, amazingly, 8 termite species that host the protist-microbe holobionts). Importantly, this strict co-speciation has been maintained despite physical mixing of protists between termite species! In other words, bacteria had had ample opportunity to "betray" their host protists, and protists had had the chance to "switch" to a different species of termite. This, however, 
has not happened, which demonstrates the intimate, vertically continuous character of this relationship.

In a different study (Edgcomb et al. 2011a) it was found that in the evolution of symbiontid host-epibiont associations, there is not only agreement of tree topology (i.e. there is co-speciation), but also branch lengths. It means that after the emergence of the new species, the host-epibiont pair undergoes the same amount of molecular evolution, which means not only that the lineages have been coupled, but also that the coupled organisms likely accumulated a similar measure of morphological or metabolic novelty.

\subsection{Summary}

The four above-described scales allows for a clear, unequivocal description of the tightness of association between the host and the associated organisms. They are summarized in Table 1.

Table 1 spans the full scope of possible supra-organismal associations. The two endpoints of the scale would be:

a. no negative consequences of separation, no spatial order, no anatomical adaptations, no phylogenetic signs of co-evolution;

b. death upon separation, actively maintained spatial order, anatomical adaptations, clear phylogenetic signs of co-evolution.

In Sect. 7, this scale will be discussed in the context of the debate on the term "superorganism".

\section{Prokaryotic Tissues and Organs of Eukaryotic Cells}

In the protist kingdom there seems to be a level of structural (anatomical) complexity that demands a separate discussion. Among the relevant biological concepts that seem most applicable, two will be discussed: tissue and organ.

To the best of my knowledge, there have been no systematic studies of the applicability of the terms "tissue" and "organ" to multi-species superorganisms. The term "organ" was briefly discussed in that context by Bordenstein and Theis (2015) and their conclusion was expressed as "Principle II" (of their "10 Principles of Holobionts and Their Hologenomes") which says that "Holobionts and hologenomes are not organ systems, superorganisms, or metagenomes". Likening holobionts to organs/organ systems is an interesting proposal because it invites analyses of their functional unity. Bordenstein and Theis, however, conclude that this analogy can not be made, however their reasons are not of functional, but genetic nature. According to their definitions, organ systems are "biological entities comprised of one organism's genome" (p. 3), i.e. it has been assumed in the definition that the term can only encompass parts of a single multicellular organism. This is unfortunate, because only a more functional approach, like the one argued for below, might shed more light on the real level of complexity and internal unity of holobionts. This was however, admittedly, not the main point of Bordenstein and Theis. 


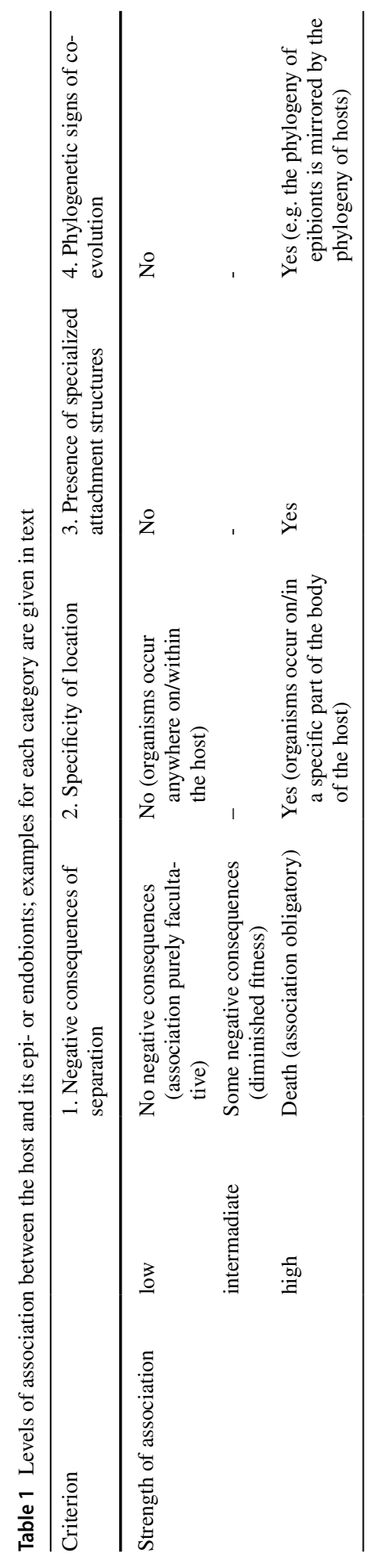




\subsection{Tissues}

"Tissue" is usually defined as a collection of similar cells that together carry out a specific function-a definition that is relatively easy to be met. Histology textbooks, however, tend to add some more detail to this definition. One standard textbook (Ross and Pawlina 2017, p. 92) adds that (a) cells within tissues communicate through specialized junctions, and that (b) the aggregation of cells is spatially organized.

In certain protist-microbe associations discussed above not only the basic definition, but also the additional conditions are clearly met. Specifically, the epibiotic covers of Symbiontida or Oxymonadida are definitely tissues by that extended definition, and their similarities to the animal epidermis are striking:

- both fully cover the organism, save for a small section immediately adjacent to the opening through which food in ingested (cytostome in the protist, mouth in the animal), which demonstrates tight control over the localization of cells;

- both are composed of numerous tightly-packed cells, usually connected by specialized cell regions ("knobs" in symbiontids, cell junctions in animals);

- both play a specific function for the organism; while it remains to be determined what are the actual functions played by the epibionts of the symbiontid protists, in Bihospites bacati one species has most likely a defensive function against other microorganisms, while the latter probably confers chemical protection from the environment (Breglia et al. 2010)—which is exactly the function(s) of epidermis;

- both, as a result, are strictly obligatory for the host; the removal of the epibiotic cover of an oxymonad (Leander and Keeling 2004) leads to the death of the host - which is what would happen to a fully skinned human being.

\subsection{Organs}

Tissues are often referred to as the intermediate level of organization between the cell and the organ. An organ, in turn, is usually defined (e.g. Van Lommel 2003, p. 123) as a structure composed of numerous tissues that together carry out a single function. What follows is an analysis whether this definition can be applied to protist-prokaryote associations.

\subsubsection{Prokaryotic "Skins" of Unicellular Protists}

As discussed in Sect. 5.2, in Bihospites bacati there are two species of "epidermis"-forming bacteria, which are underlain by a third layer of mitochondrion-derived organelles. If each cell types forms one tissue, then there are in fact two tissues forming the epidermis, arranged in longitudinal strips, and an additional "tissue" of the submembrane organelles (whether one accepts them as a tissue, depends on whether one would qualify mitochondria, or their descendants, as cells). In the oxymonad Streblomastix thrix there are at least three different morphotypes of surface-attached prokaryotes, but functional separation between them is not clear, so this example merits further study.

The parabasalid Mixotricha paradoxa is probably an even more striking example, because its epibiotic cover is composed of two species of prokaryotes that seem to have completely different functions for the host (Cleveland and Grimstone 1964). The surface of the protist, as already mentioned in Sect. 5.3, contains small projections called "brackets", 
to each of which two bacterial cells are attached: one spirochaete, directed to the posterior part of the host cell, and one rod-shaped bacterium, laying flatly at the anterior side. Mixotricha is completely dependent on its epibiotic spirochaetes with its movement: although it contains flagella, they are small and play a role only in directing movement, but not in actually propelling the protist. This is demonstrated by the observation (Cleveland and Grimstone 1964) that the flagella are often motionless, and yet the protist moves, while its surface-attached spirochaetes beat in an orderly, highly organized fashion. Each bacterium moves in coordination to its neighbours, and waves appear at the surface, originating at the tip of the host cell. In short, the population of bacteria are the organ of locomotion for the protist. The function of the rod-shaped bacteria is as yet unknown, but it is not locomotory (Wenzel et al. 2003) - it might, for instance mediate in the interactions between the prostist and the spirochaetes, or play a completely different role altogether.

In both of these cases, especially the latter one, the epibiotic cover is complex enough to merit likening it to skin (which is an organ), rather than simply to epidermis (which is a tissue). If a tissue is to be composed of "similiar" cells, then the two strikingly different prokaryotic species comprising the epibiotic cover of Mixotricha should be called an organ composed of two types of tissue. In case of Bihospites, on the other hand, there would be analogues to both the epidermis (composed of two cell types) and the "deep skin" (composed of hydrogenosome-type organelles).

\subsubsection{Other Multi-cellular Structures}

There are other examples of structures that seem to satisfy the definition of "organ". For the purposes of the present study, one example should suffice.

"Kidney-shaped vesicles" (KSVs) were found in the unidentified anoxic ciliate related to Parduczia orbis (Edgcomb et al. 2011b). These double-membrane bound organelles are consistently located in the dorso-central zone of the ciliate body, and contain no less than 3 (and up to 6) different morphotypes of bacteria (see Fig. 4): one long, elliptical in cross section, immediately adjacent to the inner leaflet of the KSV membrane, and two or more further morphotypes interspersed in the inner core of the KSV. There is usually a number of adjacent KSVs, forming a "battery", and between individual vesicles there is a population of hydrogenosome-like organelles (arrowheads in Fig. 4). Edgcomb et al. (2011b) hypothesize that the function of KSVs is metabolic: the vesicle function in combining the sulfur cycle with the carbon and nitrogen cycles of the host, allowing it to function in a high-sulfur, anoxic environment.

\section{Summary and Discussion}

\subsection{Protist-Prokaryote Associations are Holobionts, Superorganisms and Individuals}

If the term "holobiont" is to be understood as a "unit of biological organization composed of a host and its microbiota" (Bordenstein and Theis 2015), then all examples of protistprokaryote association fulfill this definition, including all cases of ecto- and endosymbiosis which, as mentioned above, are extremely common in nature, even ones that are fully 
facultative, such as the association of Trachelomonas with epibionts discussed in Sect. 5.1 (Rosowski and Couté 1996).

Even with the more narrow definition by Guerrero et al. (2013) who considered the holobiont to be a "permanent coexistence of various bionts" (Guerrero et al. 2013, emphasis mine), all examples discussed here where the association of obligatory (i.e. all those found in oxymonads, symbiontids, parabasalids and ciliates, but also in cases such as Paulinella) can be called holobionts.

The concept of a multi-species superorganism seems to offer a slightly higher selectivity, as it emphasises division of function, not simply physical coexistence (note e.g. the definition by Wilson and Sober (1989) discussed in Sect. 2). However, in reality, all the cases that satisfy the narrower definition of holobiont sensu Guerrero et al. (2013), simultaneously satisfy this definition of superorganism. While it is conceivable that there be obligatory coexistence without functional division, to my knowledge this is not realized in any protist, i.e. all holobionts sensu Guerrero et al. are also superorganisms sensu Wilson and Sober, and conversely.

Based on the evidence presented in Sect. 5 it is clear that the protist-prokaryote associations such as Bihospites bacati and Mixotricha paradoxa are both physiological individuals and evolutionary individuals sensu Pradeu (2012). The obligatory character of associations and specificity of location (criteria 1 and 2 from Table 1) demonstrate the former and the presence of specialized attachments structures and phylogenetic signs of coevolution (criteria 3 and 4) demonstrate the latter.

Interestingly, Pradeu explicitly states that the immunological criterion of individuality can hold not only for multicellular organisms, but also for unicellular organisms (Pradeu

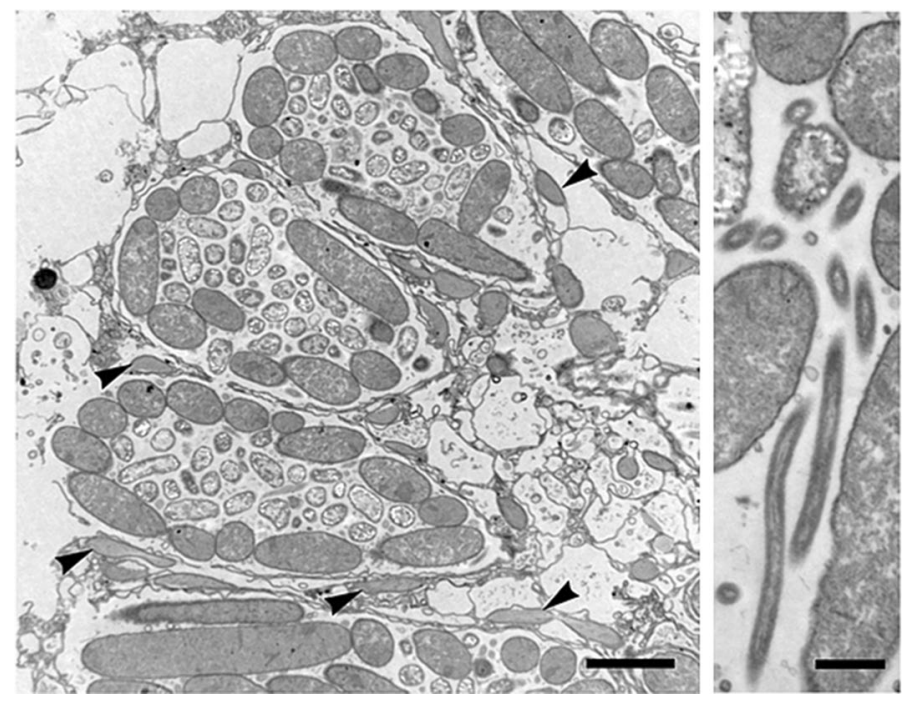

Fig. 4 "Kidney-shaped vesicles" of an anoxic ciliate described by Edgcomb et al. (2011b). The image on the left shows the general morphology of three such structures. Two main types of bacteria are readily visible: (1) a larger, darker morphotype, encircling the vesicle from the inside, (2) smaller, brighter, filling the inside of the vesicle. The image on the right shows the third, less conspicuous morphotype discussed by Edgcomb et al.: thin, curved rods, interspersed between the other two. Overall, the structure is highly spatially and functionally organized 
Fig. 5 Close-up of the physical association between Bihospites bacati and its surface bacteria [from: Breglia et al. 2010]. Both images are cross-sections of the folded ("wrinkled") surface of the protist cell; for context, see Fig. 2c. The top image shows four S-shaped folds (S), each covered at the top by smaller, spherical-shaped bacteria (black arrowheads), with larger, rodshaped bacteria (white arrowheads) laying at the bottoms of the "troughs" separating the folds. Each spherical fold contains a specialized structure, the mitochondrionderived organelle (MtD) that likely assists in the metabolic exchange between the protist and the bacteria. Extrusomes (E) are visibile as well. The bottom image is a magnification of the point of contact between the protist and two sphericalshaped bacteria. Immediately between the cells of the protist and the bacterium there is a specialized attachment structure (double arrowhead, GL). Overall, these two image demonstrate that the protist-bacteria association is highly specialized, the bacteria are placed in well-defined locations and the host produces numerous structures (the S-folds, the MtD organelles, the GL attachment) to accommodate the bacteria.

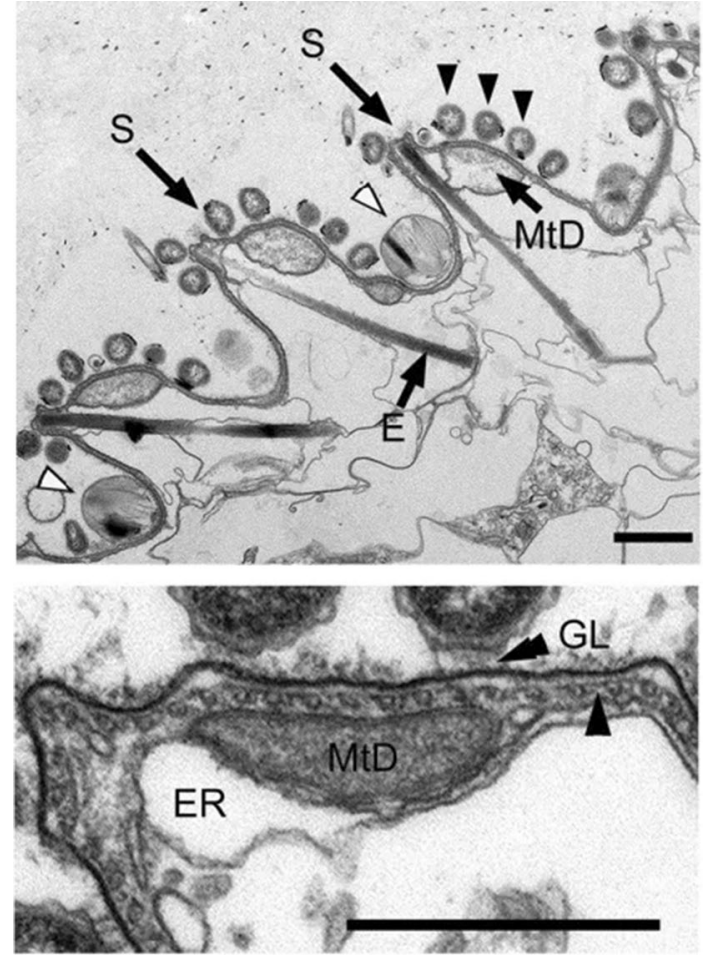

2012, p. 241). However, there are no such specific examples of unicellular eukaryoteprokaryote association discussed in his texts nor in the relevant literature, although protists are mentioned in passing in some papers, e.g. in Chiu and Eberl (2016). The existence of an "immune system" in protists is not a trivial issue and the applicability to them of Pradeu's criterion merits a separate work. However, as a preliminary observation, one might note that many protists do have organelles of defense (such as extrusomes) and intracellular mechanisms for the digestion of intruding cells — and any actively maintained populations of epibionts or endobionts are, almost by definition, not targeted by these systems. Bihospites bacati, for instance, has both epibiotic bacteria and extrusomes (see Fig. 5). Is is therefore likely that if one decided to explicitly define immunogenic self-nonself relations for protists, then protist-prokaryote associations described in the present work would meet Pradeu's definition of immunological individuals as well.

\subsection{Anatomical and Functional Complexity: The Need for an Expanded Vocabulary}

There is one aspect of protist-prokaryote associations that merits separate discussion. All of the above-cited authors seem to be blind to anatomical and functional complexity, and their definitions apply equally well to cases where there is a single species of microbiota randomly interspersed in the host cytoplasm (e.g. Paulinella chromatophora), and those that have multiple species, functionally interdependent and spatially organized in a very 
specific manner, i.e. have tissues and organs in the sense explained in Sect. 6. This most likely results from two factors:

a. the choice of examples that do not exhibit tissue-type spatial organization: for instance, Wilson and Sober (1989), but also Gordon et al. (2013), discuss almost exclusively single-species superorganisms, such as insect colonies;

b. focus on theoretical biology and genetics, not on cell biology and anatomy.

Anatomical and functional complexity of real-world superorganisms is, as a result, largely ignored and the existing definitions leave out the rich biological content described in Sects. 5 and 6. This, however, is traditionally emphasized in other areas of biology. In zoology, for instance, there is a division of animals into tissue-bearing Histozoa (which are probably a clade), and the rest, sometimes termed "Ahistozoa". In phycology, the level of complexity of cell-to-cell interactions is expressed by the various names for types of organization: unicellular, palmelloid, coccoid, sarcinoid, filamentous, thallose etc., and even now, when it is known that these grades are not good phylogenetic markers, it is still in practical use (Van den Hoeck et al. 1995, p. 334n).

In this spirit, I propose the term structured superorganism to encompass all superorganisms sensu Wilson and Sober (1989) in which at least one species has the level of organization typical for tissues, as defined by Ross and Pawlina (2017). (The present paper is therefore a review of all known cases of structured multi-species superorganisms in which the host is a unicellular protist.)

Synthetically, this definition entails:

- an association, i.e. a collection of organisms that are physically attached to each other throughout most of their lives (usually: all of their lives);

- an association that has "the functional organization implicit in the formal definition of organism" (Wilson and Sober 1989), i.e. different organisms that make up the superorganism have different functions;

- obligatory nature of the association, i.e. creatures are non-viable after separation;

- presence of specialized cell-cell attachments;

- specificity of localization of the organisms in the association ("spatial organization").

Of the species discussed in this paper, the following protists certainly satisfy the definition: Bihospites bacati, Calkinsia aureus, Mixotricha paradoxa, Joenia annectens, Kentrophoros $s p$. The applicability of the definition to other species requires further study, for instance in the case of Streblomastix thrix, where the functional organization of the superorganism has not yet been determined. In fact, it seems clear, that an impartial study of Bihospites bacati, Joenia annectens or the KSV-bearing ciliate-one that would abstract from the genetic identity of the cells comprising these superorganisms, and simply focus on their structural and functional complexity-would lead to the description of those entities as multicellular organisms with tissues and/or organs.

Generally speaking, structured multi-species superorganisms in which the host is a unicellular protist seem to have evolved independently in at least three monophyletic groups: the symbiontids, the oxymonads and the parabasalids.

Overall, the conclusions of the present study are that: 
- The terms "holobiont" and "superorganism", as normally defined in the literature, can be applied to certain protist-microbe associations and are useful in describing the complexity of the relationships between the eukaryotes and the prokaryotes. The same is true for the terms "physiological individual" and "evolutionary individual" and, tentatively, "immunological individual" sensu Pradeu (2012).

- The existing terminology does not capture in a satisfactory way the level of structural and functional complexity found in nature, especially amongst the unicellular eukaryotes, members of the kingdom Protista. This merits the creation of a new term, that would specifically encompass those superorganisms that exhibit tissue- and organ-like complexity. I propose the name structured superorganism.

- The study of protists offers great value to the study of the foundations of biology. The kingdom Protista presents an enormous anatomical, physiological and ecological variability, largely unknown to scholars outside the field of protistology. The diversity of form and function, especially at the level of individual cells, much surpasses anything that is known from the three multicellular kingdoms, i.e. Animalia, Fungi and Plantae. Each year discoveries are made that force us to rethink basic concepts of biology, such as "cell", "organism", "tissue" or "organ"- discoveries that are not curiosities or outliers, but key pieces of information for the foundational questions of biology. It is of critical importance to present the current state of knowledge of microscopic eukaryotes to the general audience of biologists and philosophers of biology.

Acknowledgements I wish to express my gratitude to Matt Haber for referring me to T. Pradeu’s work.

\section{Compliance with Ethical Standards}

Conflict of interest The author states that there is no conflict of interest.

Open Access This article is licensed under a Creative Commons Attribution 4.0 International License, which permits use, sharing, adaptation, distribution and reproduction in any medium or format, as long as you give appropriate credit to the original author(s) and the source, provide a link to the Creative Commons licence, and indicate if changes were made. The images or other third party material in this article are included in the article's Creative Commons licence, unless indicated otherwise in a credit line to the material. If material is not included in the article's Creative Commons licence and your intended use is not permitted by statutory regulation or exceeds the permitted use, you will need to obtain permission directly from the copyright holder. To view a copy of this licence, visit http://creativecommons.org/licenses/by/4.0/.

\section{References}

Bordenstein, S. R., \& Theis, K. R. (2015). Host biology in light of the microbiome: ten principles of holobionts and hologenomes. PLoS biology, 13(8), e1002226.

Bouchard, F., \& Huneman, P. (Eds.). (2013). From groups to individuals: Evolution and emerging individuality. Cambridge: MIT Press.

Breglia, S. A., Yubuki, N., Hoppenrath, M., \& Leander, B. S. (2010). Ultrastructure and molecular phylogenetic position of a novel euglenozoan with extrusive episymbiotic bacteria: Bihospites bacati n. gen. et sp.(Symbiontida). BMC Microbiology, 10(1), 145.

Čepička, I., Dolan, M. F., \& Gile, G. H. (2017). Parabasalia. In J. M. Archibald, A. G. Simpson, C. H. Slamovits, L. Margulis, M. Melkonian, D. J. Chapman, \& J. O. Corliss (Eds.), Handbook of the protists. Berlin: Springer. 
Chen, T., Yu, W. H., Izard, J., Baranova, O. V., Lakshmanan, A., \& Dewhirst, F. E. (2010). The Human Oral Microbiome Database: A web accessible resource for investigating oral microbe taxonomic and genomic information. Database, 2010.

Chiu, L., \& Eberl, G. (2016). Microorganisms as scaffolds of host individuality: an eco-immunity account of the holobiont. Biology and Philosophy, 31(6), 819-837.

Cleveland, L. R., \& Grimstone, A. V. (1964). The fine structure of the flagellate Mixotricha paradoxa and its associated micro-organisms. Proceedings of the Royal Society of London. Series B. Biological Sciences, 159(977), 668-686.

Desai, M. S., Strassert, J. F., Meuser, K., Hertel, H., Ikeda-Ohtsubo, W., Radek, R., et al. (2010). Strict cospeciation of devescovinid flagellates and Bacteroidales ectosymbionts in the gut of dry-wood termites (Kalotermitidae). Environmental Microbiology, 12(8), 2120-2132.

Dietert, R., \& Dietert, J. (2012). The completed self: an immunological view of the human-microbiome superorganism and risk of chronic diseases. Entropy, 14(11), 2036-2065.

Dyer, B. D., \& Khalsa, O. (1993). Surface bacteria of Streblomastix strix are sensory symbionts. Biosystems, 31(2-3), 169-180.

Edgcomb, V. P., Breglia, S. A., Yubuki, N., Beaudoin, D., Patterson, D. J., Leander, B. S., et al. (2011a). Identity of epibiotic bacteria on symbiontid euglenozoans in O 2-depleted marine sediments: evidence for symbiont and host co-evolution. The ISME Journal, 5(2), 231.

Edgcomb, V. P., Leadbetter, E. R., Bourland, W., Beaudoin, D., \& Bernhard, J. (2011b). Structured multiple endosymbiosis of bacteria and archaea in a ciliate from marine sulfidic sediments: A survival mechanism in low oxygen, sulfidic sediments? Frontiers in Microbiology, 2, 55.

Fenchel, T., \& Finlay, B. J. (1989). Kentrophoros: A mouthless ciliate with a symbiotic kitchen garden. Ophelia, 30(2), 75-93.

Foissner, W. (1995). Kentrophoros (Ciliophora, Karyorelictea) has oral vestiges: A reinvestigation of K. fistulosus (Fauré-Fremiet, 1950) using protargol impregnation. Archiv für Protistenkunde, 146(2), $165-179$.

Gardner, A., \& Grafen, A. (2009). Capturing the superorganism: a formal theory of group adaptation. Journal of Evolutionary Biology, 22(4), 659-671.

Goodacre, R. (2007). Metabolomics of a superorganism. The Journal of Nutrition, 137(1), 259S-266S.

Gordon, J., Knowlton, N., Relman, D. A., Rohwer, F., \& Youle, M. (2013). Superorganisms and holobionts. Microbe, $8(4), 152-153$.

Guerrero, R., Margulis, L., \& Berlanga, M. (2013). Symbiogenesis: the holobiont as a unit of evolution. Int Microbiol, 16(3), 133-143.

Haber, M. (2013). Colonies are individuals: Revisiting the superorganism revival. In F. Bouchard \& P. Huneman (Eds.), From groups to individuals: Evolution and emerging individuality (pp. 195-217). Cambridge: MIT Press.

Hampl, V. (2017). Preaxostyla. In J. M. Archibald, A. G. Simpson, C. H. Slamovits, L. Margulis, M. Melkonian, D. J. Chapman, \& J. O. Corliss (Eds.), 2017. Springer, Berlin: Handbook of the Protists.

Hull, D. L. (1988). Science as a process: An evolutionary account of the social and conceptual. Chicago: Chicago University Press.

Kesebir, S. (2012). The superorganism account of human sociality: How and when human groups are like beehives. Personality and Social Psychology Review, 16(3), 233-261.

Leander, B. S., \& Keeling, P. J. (2004). Symbiotic innovation in the oxymonad Streblomastix strix. Journal of Eukaryotic Microbiology, 51(3), 291-300.

Leander, B., \& Yubuki, N. (2018). Diversity and evolutionary history of the Symbiontida (Euglenozoa). Frontiers in Ecology and Evolution, 6, 100.

Linksvayer, T. A., Busch, J. W., \& Smith, C. R. (2013). Social supergenes of superorganisms: Do supergenes play important roles in social evolution? BioEssays, 35(8), 683-689.

Lynn, D. H. (2008). The ciliated protozoa. Berlin: Springer.

Mai, V., \& Draganov, P. V. (2009). Recent advances and remaining gaps in our knowledge of associations between gut microbiota and human health. World Journal of Gastroenterology: WJG, 15(1), 81.

Margulis, L. (1991). Symbiogenesis and symbionticism. In L. Margulis \& R. Fester (Eds.), Symbiosis as a source of evolutionary innovation: Speciation and morphogenesis (pp. 1-15). Cambridge: MIT Press.

Noda, S., Inoue, T., Hongoh, Y., Kawai, M., Nalepa, C. A., Vongkaluang, C., et al. (2006). Identification and characterization of ectosymbionts of distinct lineages in Bacteroidales attached to flagellated protists in the gut of termites and a wood-feeding cockroach. Environmental microbiology, 8(1), 11-20.

Nowack, E. C., \& Melkonian, M. (2010). Endosymbiotic associations within protists. Philosophical Transactions of the Royal Society B: Biological Sciences, 365(1541), 699-712. 
Ohkuma, M., Noda, S., Hattori, S., Iida, T., Yuki, M., Starns, D., et al. (2015). Acetogenesis from $\mathrm{H}_{2}$ plus $\mathrm{CO}_{2}$ and nitrogen fixation by an endosymbiotic spirochete of a termite-gut cellulolytic protist. Proceedings of the National Academy of Sciences, 112(33), 10224-10230.

Petroni, G., Spring, S., Schleifer, K. H., Verni, F., \& Rosati, G. (2000). Defensive extrusive ectosymbionts of Euplotidium (Ciliophora) that contain microtubule-like structures are bacteria related to Verrucomicrobia. Proceedings of the National Academy of Sciences, 97(4), 1813-1817.

Pradeu, T. (2012). The limits of the self: immunology and biological identity. Oxford: Oxford University Press.

Pradeu, T. (2016). Organisms or biological individuals? Combining physiological and evolutionary individuality. Biology and Philosophy, 31(6), 797-817.

Preer, J. R., Jr., Preer, L. B., \& Jurand, A. R. T. U. R. (1974). Kappa and other endosymbionts in Paramecium aurelia. Bacteriological Reviews, 38(2), 113.

Rosenberg, E., \& Zilber-Rosenberg, I. (2011). Symbiosis and development: The hologenome concept. Birth Defects Research Part C: Embryo Today: Reviews, 93(1), 56-66.

Rosenberg, E., \& Zilber-Rosenberg, I. (2014). The hologenome concept: Human, animal and plant microbiota. Berlin: Springer.

Rosowski, J. R., \& Couté, A. (1996). Bacteria on the lorica of Trachelomonas occur in nature, not just in culture. Journal of Phycology, 32(4), 697-698.

Rosowski, J. R., \& Langenberg, W. G. (1994). The near-spineless Trachelomonas grandis (Euglenophyceae) superficially appears spiny by attracting bacteria to its surface 1, 2. Journal of Phycology, 30(6), 1012-1022.

Ross, M., \& Pawlina, W. (2017). Histology, A text and atlas, with correlated cell and molecular biology. Philadelphia: Lippincott Williams and Wilkins.

Scott, G. D. (1969). Plant symbiosis. London: Edward Arnold.

Stencel, A., \& Proszewska, A. M. (2018). How research on microbiomes is changing biology: A discussion on the concept of the organism. Foundations of Science, 23(4), 603-620.

Strassert, J. F., Desai, M. S., Radek, R., \& Brune, A. (2010). Identification and localization of the multiple bacterial symbionts of the termite gut flagellate Joenia annectens. Microbiology, 156(7), 2068-2079.

Treitli, S. C., Kolisko, M., Husník, F., Keeling, P. J., \& Hampl, V. (2019). Revealing the metabolic capacity of Streblomastix strix and its bacterial symbionts using single-cell metagenomics. Proceedings of the National Academy of Sciences, 116(39), 19675-19684.

Trenchard, H. (2015). The peloton superorganism and protocooperative behavior. Applied Mathematics and Computation, 270, 179-192.

Van den Hoeck, H., Mann, D., \& Jahns, H. M. (1995). Algae: An introduction to phycology. Cambridge: Cambridge University Press.

Van Lommel, A. T. (2003). From cells to organs: A histology textbook and atlas. Berlin: Springer.

Wenzel, M., Radek, R., Brugerolle, G., \& König, H. (2003). Identification of the ectosymbiotic bacteria of Mixotricha paradoxa involved in movement symbiosis. European journal of protistology, 39(1), 11-23.

Wilson, D. S., \& Sober, E. (1989). Reviving the superorganism. Journal of theoretical Biology, 136(3), 337-356.

Winkler, I. S., \& Mitter, C. (2008). The phylogenetic dimension of insect-plant interactions: A review of recent evidence. Specialization, Speciation, and Radiation: The Evolutionary Biology of Herbivorous Insects, pp. 240-263.

Yubuki, N., Edgcomb, V. P., Bernhard, J. M., \& Leander, B. S. (2009). Ultrastructure and molecular phylogeny of Calkinsia aureus: Cellular identity of a novel clade of deep-sea euglenozoans with epibiotic bacteria. BMC microbiology, 9(1), 16.

Yubuki, N., \& Leander, B. S. (2018). Diversity and evolutionary history of the Symbiontida (Euglenozoa). Frontiers in Ecology and Evolution, 6, 100.

Łukasz Lamża is a philosopher, currently at the Copernicus Center for Interdisciplinary Studies, Jagiellonian University in Krakow, Poland. His main area of interest is philosophy of cosmology, astrophysics, and planetary and biological evolution, especially the systematic study of processes that cause the increase of natural complexity. A member of the A.N. Whitehead Metaphysical Society in Katowice, he is also active in promoting the works of Alfred N. Whitehead in Poland (including translating important works in process philosophy for the Polish readers) and in developing process philosophy and metaphysics of nature. 